\title{
Does substance use affect educational outcomes?
}

\section{There is little evidence that substance use reduces educational attainment}

Keywords: alcohol, marijuana, school dropout, human capital, grade point average

\section{ELEVATOR PITCH}

A non-trivial portion of traffic fatalities involve alcohol or illicit drugs. But does the use of alcohol and illegal substances-which is linked to depression, suicide, and criminal activity-also reduce academic performance? Recent studies suggest that drinking alcohol has a negative, if modest, effect on grades, and although students who use illegal substances are more likely to drop out of school than those who do not, this may reflect the influence of other, difficultto-measure factors at the individual level, such as personality.

\section{KEY FINDINGS}

\section{Pros}

$\oplus$ Alcohol consumption has only a modest effect on academic performance as measured by grades.

๑ Even binge drinking appears to have, at most, a modest impact on academic performance.

๑ Alcohol use does not appreciably reduce the probability of attending, or graduating from, university.
Percentage of US 18- to 20-year-olds who used an illicit drug in the previous month

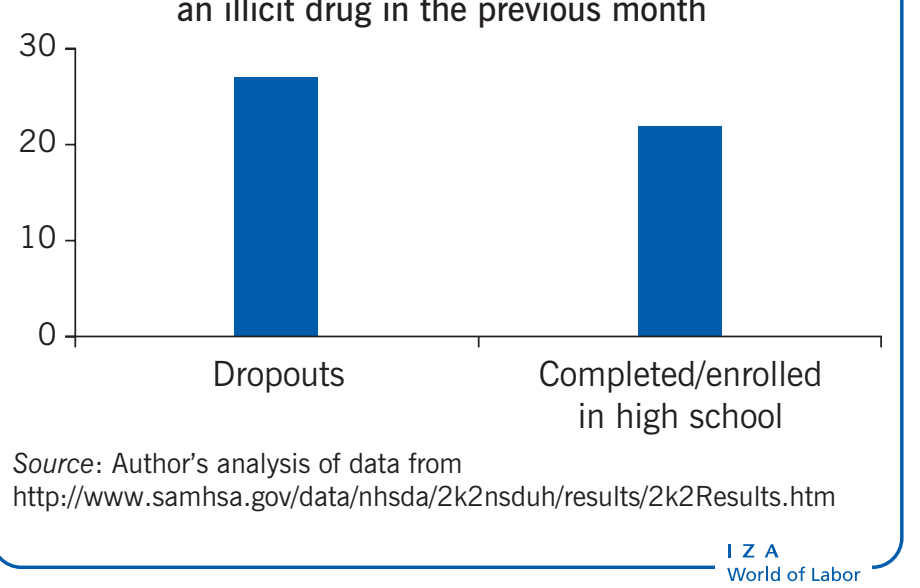

\section{AUTHOR'S MAIN MESSAGE}

The effect of alcohol use on educational attainment appears to be either small or non-existent. Although alcohol use may have a negative impact on academic performance, this effect also appears to be modest. Illicit drug use is associated with poor educational outcomes, but no causal relationship has been demonstrated. Illicit drug use is unresponsive to policy, so credible natural experiments are rare. Without them, the effects of substance use cannot be distinguished from those of personal characteristics. Given these results, it is difficult to make a strong case for policy intervention. 


\section{MOTIVATION}

There is a variety of reasons why substance use might affect such educational outcomes as grades and the probability of graduation. For instance, substance use could divert time and energy away from studying. It is also possible that substance use is causally related to educational outcomes through its effects on cognitive functioning, attention span, short-term memory, or even self-esteem.

Of the many empirical studies on this topic, only a few provide credible estimates of the causal effects of substance use. Illicit drug use by students appears to be largely unresponsive to policy, making convincing natural experiments exceedingly rare. In contrast, the minimum legal drinking age appears to generate substantial changes in alcohol consumption, providing researchers with a method of obtaining credible estimates.

\section{DISCUSSION OF PROS AND CONS}

Numerous studies have documented a negative association between substance use and educational outcomes. This association is alarming because society benefits when its members are informed and educated. But is it causal, or can it be ascribed to difficult-tomeasure factors at the individual level, such as personality, family background, and how much an individual discounts future outcomes?

The cleanest, surest method of establishing causality would be to conduct a randomized controlled experiment. For instance, imagine randomly assigning students to treatment and control groups, ensuring that neither group has a disproportionate share of impulsive risk-takers. The treatment group would agree to use marijuana (or some other substance) as directed, while the control group would have no choice but to abstain. After some period of time, the effects of marijuana use on educational attainment (for example, graduation from high school) and academic performance (for example, test scores or grades) could be ascertained by simply comparing the two groups.

Because the experiment described above might raise eyebrows, researchers have increasingly turned to the next best thing: natural experiments. A natural experiment exploits an isolated change in conditions or incentives facing a subpopulation (often due to implementation of a government policy), but leaves an otherwise comparable subpopulation essentially untouched. If such a change is sufficiently abrupt-and sufficiently large-then it can be used in making causal inferences.

Only a handful of studies have attempted to use a clearly defined natural experiment to estimate the effect of substance use on student outcomes such as grades and the probability of graduating from high school. Some researchers have attempted to produce what they describe as causal estimates by exploiting cross-sectional policy variation or making sure that the substance use took place prior to the particular outcome under study. However, without a clearly defined natural experiment, it can be challenging to distinguish the effects of substance use from those of personality or family background.

\section{Government policies and alcohol use}

As noted, natural experiments are often based on a policy that changes the incentives facing a subpopulation. An obvious example would be a state excise tax on alcoholic 
beverages. A number of studies using data from the US have examined the relationship between beer taxes and youth drinking. Their results have been decidedly mixed.

In contrast, the evidence for the relationship between the minimum legal drinking age and alcohol consumption is much stronger. A number of studies have found that increasing the minimum legal drinking age from 18 to 21 discourages drinking. In addition, there is evidence that alcohol consumption increases sharply at the minimum legal drinking age.

\section{Alcohol use and academic performance}

The sharp increase in alcohol consumption at the minimum legal drinking age has been exploited by researchers who are interested in the determinants of academic performance as measured by grades. For instance, a 2011 study based on data from the United States Air Force Academy found that gaining legal access to alcohol at age 21, the minimum legal drinking age, leads to a reduction in test scores of one-tenth of a standard deviation [1]. Although this reduction was precisely estimated, it may not reflect what happens when the typical university student gains legal access to alcohol. The Air Force Academy is extremely selective, most of its students are male, and most go on to become commissioned officers in the United States Air Force. Furthermore, underage drinking is strictly prohibited at the Academy, a policy that could discourage high school students who are disposed to drinking from applying.

A recent study based on data from the University of Oregon used a similar empirical strategy to estimate the relationship between alcohol consumption and academic performance [2]. Students at the University of Oregon can be thought of as representative of students at public four-year institutions in the US. Academic performance fell when students turned 21 before the end of an academic term (see Figure 1). Specifically, turning 21 is associated with a 0.03 decrease in grade point average (or GPA)-relative to a mean GPA of 3.11 among students in the sample. Moreover, using data on US students from the 1997 National Longitudinal Survey of Youth, this study found that turning 21 was associated with a substantial increase in alcohol consumption. Specifically, the mean number of days per month on which alcohol was consumed increased from 4.3 to 5.7, a rise of almost one-third.

\section{Grade point average}

Grade point average (GPA) is a common measure of academic performance in the US. It is calculated by assigning a point value to the letter grade a student receives in each class (from $A=4$ to $F=0$ ) and then taking the mean. GPA is often used by employers and universities to rate and compare applicants.

Taken together, the estimates discussed above suggest that reaching the legal drinking age leads to a modest reduction in the academic performance of university students. However, if one is interested in whether alcohol consumption affects academic performance outside the university setting, these studies are of limited value, because 
Figure 1. Normalized GPA and the minimum legal drinking age: evidence from the University of Oregon

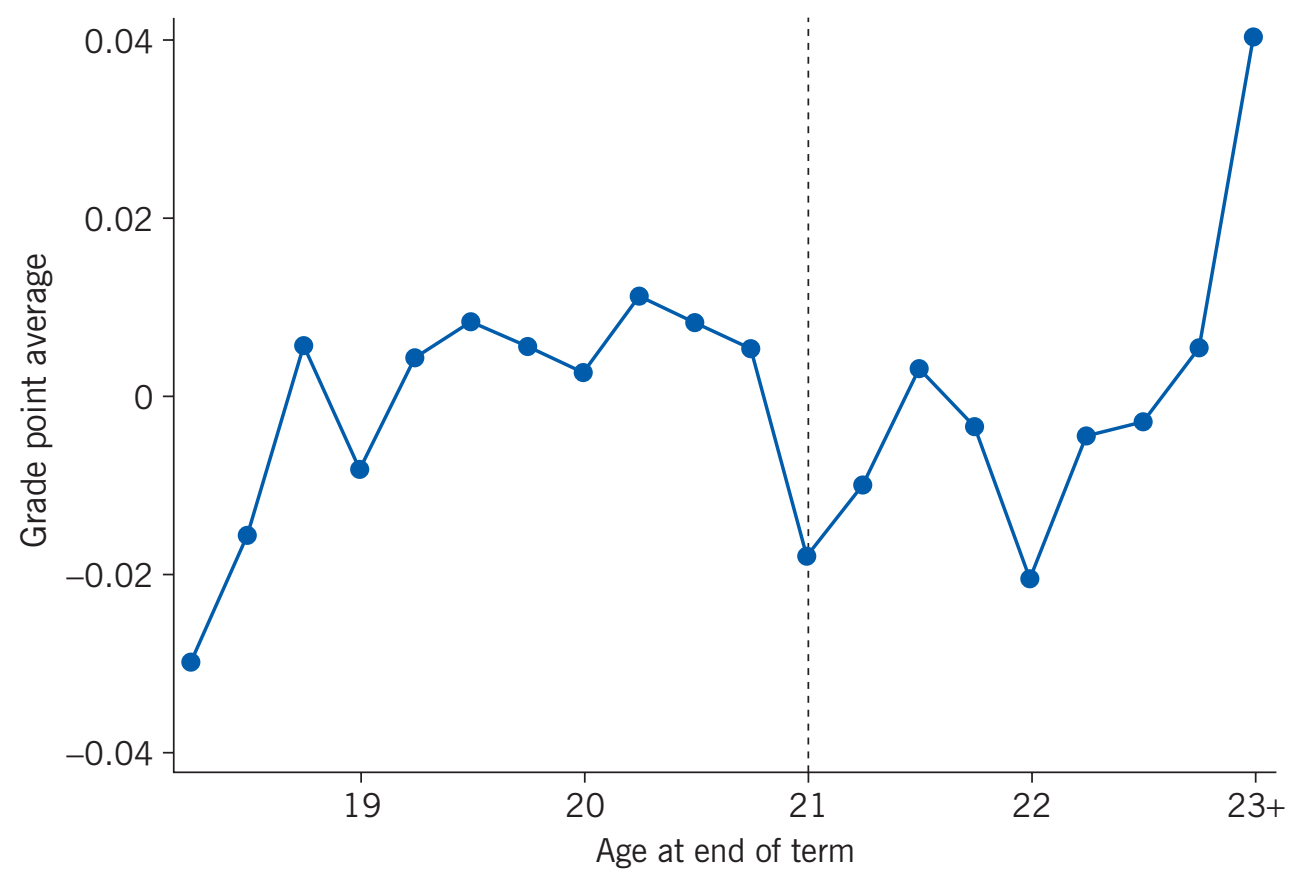

Note: Based on data for students collected over 1999-2007. Normalized GPA was adjusted for accumulated credits, course subject, level, and academic term.

Source: Lindo, J. M., I. D. Swensen, and G. R. Waddell. "Alcohol and student performance: Estimating the effect of legal access." Journal of Health Economics 32:1 (2013): 22-32 [2].

most 21-year-olds have either dropped out or graduated from high school. Moreover, due to data limitations, these studies could not pin down the mechanisms through which drinking reduces the academic performance of university students. It could be that drinking takes time away from studying. Drinking could also make it more difficult to concentrate in the classroom or lead to unexcused absences from school.

Evidence on the mechanisms through which drinking reduces academic performance comes from the National Longitudinal Study of Adolescent Health, a survey of US middle school and high school students begun in the mid-1990s. The survey asks respondents about binge drinking, defined as having five or more drinks in a row at one sitting (the standard definition used by medical researchers). Respondents still in middle school who go from not drinking to binge drinking at least twice a month experience a 0.14 0.17 reduction in GPA and are more likely to have unexcused absences [3]. There is also evidence that survey respondents who drink to excess were more likely to report having

\section{Middle school and high school in the US}

In the US, middle school typically begins in grade 6, when students are around 11 years old, and lasts for three years. Most US students move to a high school when they reach grade 9, typically at age 14 . Students graduate high school when they successfully complete grade 12 . 
trouble at school (defined as having difficulty paying attention, completing homework, or getting along with teachers).

\section{Alcohol use and educational attainment}

Although drinking appears to reduce academic performance among university students, albeit modestly, there is little evidence that it reduces educational attainment.

An often-cited US study examines what happened to drinking habits and several measures of educational attainment when states increased the minimum legal drinking age from 18 to 21 [4]. It found that restricting access to alcohol in this fashion led to sharp reductions in drinking participation, moderate drinking, and heavy drinking.

However, the study found no evidence that raising the minimum legal drinking age from 18 to 21 had an effect on educational attainment. In fact, estimates of the effects of raising the minimum legal drinking age on educational attainment, although imprecise (statistically insignificant), were often negative. For instance, increasing the minimum legal drinking age from 18 to 21 was associated with a lower probability of entering university and a lower probability of graduating from university. The estimated relationship between increasing the minimum legal drinking age and completing high school was positive, but statistically indistinguishable from zero.

\section{Government policies and the use of illegal drugs}

There is evidence from cross-sectional data of a negative association between the price of marijuana and maximum fines for its possession [5]. There is also evidence that the price of marijuana is lower in states without conditional discharge provisions (conditional discharge allows first-time offenders to have their record expunged after serving probation) [5].

Although these associations are consistent with the hypothesis that demand is sensitive to policies intended to discourage drug use, they could easily reflect difficult-to-observe factors at the state level. Because there is very little within-state variation over time in fines and other sanctions, their effects are difficult to distinguish from the effects of other policies and policing effort.

Countries such as Argentina, Colombia, Italy, Spain, and Switzerland have recently removed criminal sanctions for the use and possession of small amounts of marijuana. Decriminalization offers researchers an excellent opportunity to examine illicit drug use before and after a dramatic, well-publicized change in policy.

Some policymakers have argued that decriminalization leads to increased marijuana use [6]. However, empirical support for this argument is lacking. For instance, marijuana use among Dutch teenagers and young adults did not increase after the Netherlands decriminalized marijuana in 1976 [7]. However, "coffee-shop" commercialization, which took place after 1983, might have contributed to an increase in marijuana use among Dutch teenagers and young adults [7].

Portugal decriminalized the use and possession of all illicit drugs (including cocaine, ecstasy, heroin, marijuana, and methamphetamine) on July 1, 2001. Although the use of 
illicit drugs in Portugal increased after 2001, comparable increases took place in Italy and Spain, where these drugs had not been decriminalized [6]. Illicit drug use among 15- and 16-year-olds in Portugal appears to have increased immediately after decriminalization both in absolute terms and as compared with other countries in the European Union, but then fell from 2003 through 2007 [6].

To date, 23 states in the US and several countries (including Austria, the Czech Republic, and Israel) have legalized the use of marijuana for medical purposes (see Medical marijuana laws). The legalization of medical marijuana represents another policy change that could potentially be exploited by researchers for producing causal estimates, but there is little evidence that teenagers actually respond when these changes occur.

\section{Medical marijuana laws}

In the US, medical marijuana laws (MMLs) remove state-level penalties for using, possessing, and cultivating medical marijuana. Patients are required to obtain approval or certification from a doctor, and doctors who recommend marijuana to their patients are immune from prosecution. MMLs allow patients to designate caregivers, who can buy or grow marijuana on their behalf.

MMLs give suppliers to the medicinal market some protection against prosecution, and allow patients to buy medical marijuana without fear of being arrested or fined. Because it is prohibitively expensive for the government to ensure that all marijuana ostensibly grown for the medicinal market ends up in the hands of registered patients, it is likely that some is diverted to the illegal market. Moreover, the majority of MMLs allow patients to register as medical marijuana users based on medical conditions that cannot be objectively confirmed (e.g. chronic pain and nausea).

Historically, marijuana was officially recognized in the US as a medicinal drug from 1850 until 1942. By 1936 its recreational use had been banned in all US states, and the following year the Marihuana Tax Act effectively discontinued its use in medicine. In 1970, marijuana was listed under Schedule I of the Controlled Substances Act, a category reserved for drugs which have "high potential for abuse" and "no currently accepted medical use."

In 1996, California passed legislation decriminalising the use, possession, and cultivation of medical marijuana, and provided immunity from prosecution for physicians who recommended the use of medical marijuana to patients. Since then, 22 other states and the District of Columbia have legalized the use of medical marijuana; however, it remains classified as a Schedule I drug by the US federal government.

Source: Anderson, D. M., B. Hansen, and D. I. Rees. "Medical marijuana laws, traffic fatalities, and alcohol consumption." Journal of Law and Economics 56:2 (2013): 333-369.

An unpublished, and controversial, study examined the effect of legalizing the medical use of marijuana on US students enrolled in high school [8]. There appears to have been a slight fall in marijuana use immediately after the legalization of medical marijuana (labeled "Year of law change" in Figure 2), followed by an increase of comparable magnitude. Although the trends shown in Figure 2 are unadjusted, they suggest that 
Figure 2. Legalizing marijuana for medical use did not lead to large or abrupt changes in Cmarijuana use among US high school students

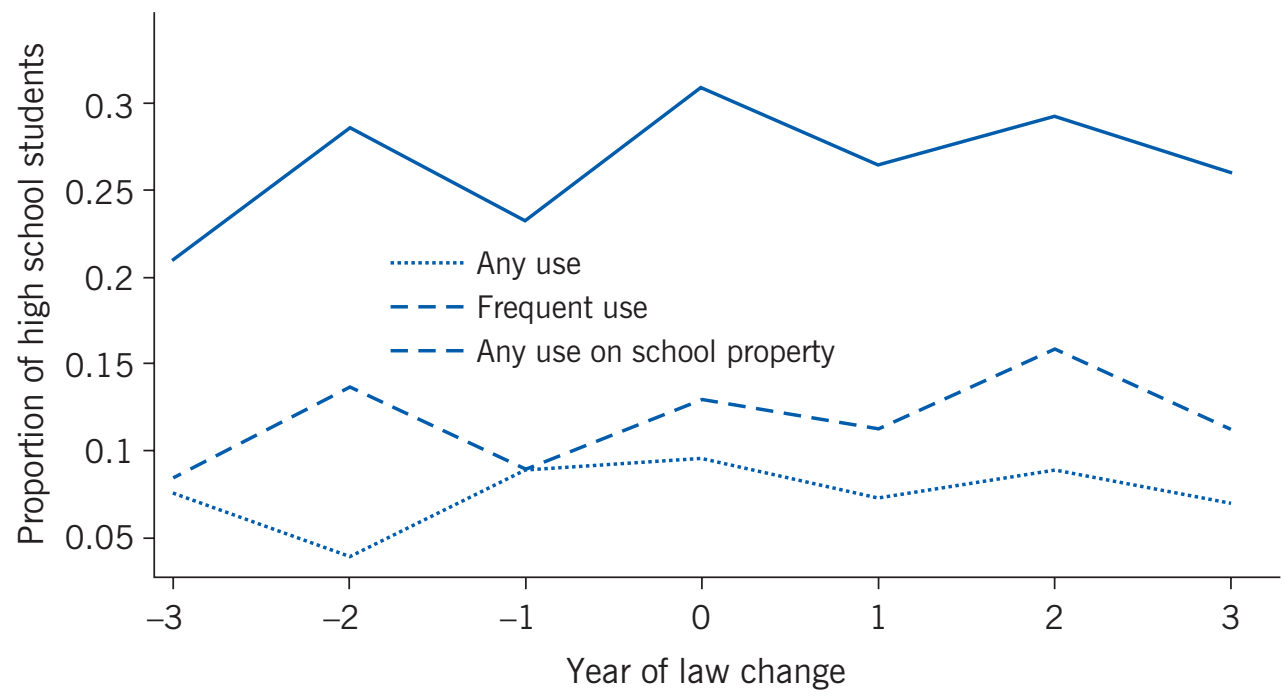

Note: Based on analysis of data from the Youth Risk Behavior Survey.

Source: Anderson, D. M., B. Hansen, and Daniel I. Rees. Medical Marijuana Laws and Teen Marijuana Use. IZA Discussion Paper No. 6592, November 2011. Online at: http://www.iza.org/en/webcontent/publications/papers/ viewAbstract?dp_id=6112 [8].

legalizing medical marijuana does not lead to an abrupt or particularly large change in behavior. Since the mid-2000s, marijuana use among US high school students has increased approximately 4 percentage points. Figure 2 provides little evidence that this increase is the result of legalizing marijuana for medical purposes. (Figure 3 provides details of when medical marijuana was legalized in different states.)

Finally, government-sponsored anti-drug programs, such as the Montana Meth Project and Project DARE (Drug Abuse Resistance Education) in the US, are often claimed by advocates to reduce the demand for illicit drugs. However, careful empirical studies suggest otherwise. The Montana Meth Project was an advertising campaign that featured billboards and television ads with extremely graphic images. After its introduction, methamphetamine use among high school students in Montana declined, but comparable declines occurred in neighboring states over the same time period [9]. More than a dozen studies have examined the impact of Project DARE, a school-based program focused on building self-esteem and teaching students to resist peer pressure, the annual cost of which is estimated to lie between $\$ 200$ million and $\$ 1$ billion [10]. Meta-analyses based on the results of the studies have concluded that Project DARE does not appreciably reduce substance use. The DARE curriculum was revised in 2003, but the revision does not appear to have increased its effectiveness [11].

\section{Illicit drugs, academic performance, and educational attainment}

Students who use illicit drugs tend to perform poorly in school. This is the case whether the student is using marijuana or harder drugs such as cocaine [12]. Moreover, the use of 
Figure 3. Medical marijuana laws in the US, 1990-2014

\begin{tabular}{ll}
\hline & \\
\hline Alaska & Effective date \\
Arizona & March 4, 1999 \\
California & May 7, 2013 \\
Colorado & November 6,1996 \\
Connecticut & June 1, 2001 \\
Delaware & October 1,2012 \\
District of Columbia & July 1,2011 \\
Hawaii & July 27, 2010 \\
Illinois & December 28, 2000 \\
Maine & January 1,2014 \\
Maryland & December 22, 1999 \\
Massachusetts & June 1,2014 \\
Michigan & January 1,2013 \\
Minnesota & December 4, 2008 \\
Montana & May 30, 2014 \\
Nevada & November 2, 2004 \\
New Hampshire & October 1,2001 \\
New Jersey & July 23, 2013 \\
New Mexico & July 1, 2010 \\
New York & July 1,2007 \\
Oregon & July 5, 2014 \\
Rhode Island & December 3, 1998 \\
Vermont & January 3, 2006 \\
Washington & July 1, 2004 \\
\hline
\end{tabular}

Source: ProCon.org. "23 Legal Medical Marijuana States and DC." Online at:

http://medicalmarijuana. procon.org/view.resource.php?resourcelD=000881 [Accessed August 20, 2014].

illicit drugs is negatively associated with educational attainment. Of 18- through 20-yearolds in the US who reported using an illicit drug in the previous month, the percentage was higher among students who had dropped out of school before graduating from high school than among those who graduated or were still in school (see lllustration on p. 1). Approximately $27 \%$ of dropouts had used an illicit drug in the previous month, compared with $22 \%$ of those who had graduated or were still in school. The negative association between illicit drug use and educational attainment is generally robust to controlling for observable characteristics such as ethnicity, family income, gender, parental education, race, and urban status.

One recent study showed that high school students in South Dakota who used marijuana were more likely to drop out of school than their counterparts who did not use marijuana [13]. However, much of this association could be explained by attitudes and behaviors measured at grade 7. The remainder was explained by concurrent cigarette use. Because there is no reason to believe that smoking should affect cognition, the authors attributed the association between marijuana use and dropping out of high school to difficult-toobserve factors at the individual level [13]. 
Because teenagers and young adults do not seem particularly responsive to changes in drug policies, at least in the short term, it is exceedingly difficult to assess whether illicit drug use does in fact affect education outcomes or whether the associations are instead spurious and attributable to individual characteristics such as personality or preferences.

\section{LIMITATIONS AND GAPS}

With only a few exceptions, the studies discussed above used data from the US. Although there is little evidence that alcohol consumption reduces educational attainment among US students, African, Asian, Australian, and European students could have different preferences or could face different challenges and incentives. As more data from outside the US become available (and studies based on these data that exploit natural experiments are published) we will be in a better position to assess whether alcohol consumption has a larger effect on educational attainment in other parts of the world.

Only a handful of studies have examined the effects of alcohol consumption using a clearly defined natural experiment. The results suggest that the effects of alcohol consumption on academic performance and educational attainment are modest or non-existent. However, it is possible that future studies will provide evidence of stronger effects.

Finally, because teenagers and young adults are not particularly responsive to changes in drug policies, it is difficult to assess whether the negative association between illicit drug use and educational attainment is causal or spurious. There is some evidence that it is spurious, but until a clearly defined natural experiment can be analyzed, doubts will (and should) remain.

\section{SUMMARY AND POLICY ADVICE}

Society benefits when its members are informed and educated. Therefore, if it could be demonstrated that substance use reduces academic performance or discourages college attendance, a case could be made for policy intervention. In fact, prominent voices have recommended higher taxes on alcohol based, in part, on the premise that alcohol consumption lowers educational attainment.

This argument is logical. However, empirical evidence for its premise is, thus far, lacking. Until more evidence can be brought to bear, attempts to restrict youth access to alcohol and other substances should be based on other concerns.

\section{Acknowledgments}

The author thanks two anonymous referees and the IZA World of Labor editors for many helpful suggestions on earlier drafts.

\section{Competing interests}

The IZA World of Labor project is committed to the IZA Guiding Principles of Research Integrity. The author declares to have observed these principles.

(c) Daniel I. Rees 


\section{REFERENCES}

\section{Further reading}

Carpenter, C. S., D. D. Kloska, P. O'Malley, and L. Johnston. "Alcohol control policies and youth alcohol consumption: Evidence from 28 years of monitoring the future." The B.E. Journal of Economic Analysis and Policy 7:1 (2007): Article 25.

Chatterji, P. "Illicit drug use and educational attainment." Health Economics 15:5 (2006): 489-511.

\section{Key references}

[1] Carrell, S. E., M. Hoekstra, and J. E. West. "Does drinking impair college performance? Evidence from a regression discontinuity approach." Journal of Public Economics 95:1-2 (2011): $54-62$.

[2] Lindo, J. M., I. D. Swensen, and G. R. Waddell. "Alcohol and student performance: Estimating the effect of legal access." Journal of Health Economics 32:1 (2013): 22-32.

[3] Sabia, J. J. "Wastin' away in Margaritaville? New evidence on the academic effects of teenage binge drinking." Contemporary Economic Policy 28:1 (2010): 1-22.

[4] Dee, T. S., and W. N. Evans. "Teen drinking and educational attainment: Evidence from twosample instrumental variables estimates." Journal of Labor Economics 21:1 (2003): 178-209.

[5] Pacula, R. L., B. Kilmer, M. Grossman, and F. J. Chaloupka. "Risks and prices: The role of user sanctions in marijuana markets." The B.E. Journal of Economic Analysis and Policy 10:1 (2010): Article 11.

[6] Hughes, C. E., and A. Stevens. "What can we learn from the Portuguese decriminalization of illicit drugs?" The British Journal of Criminology 50:6 (2010): 999-1022.

[7] MacCoun, R., and P. Reuter. "Evaluating alternative cannabis regimes." The British Journal of Psychiatry 178 (2001): 123-128.

[8] Anderson, D. M., B. Hansen, and Daniel I. Rees. Medical Marijuana Laws and Teen Marijuana Use. IZA Discussion Paper No. 6592, November 2011. Online at: http://www.iza.org/en/webcontent/publications/papers/viewAbstract?dp_id=6112

[9] Anderson, D. M. "Does information matter? The effect of the Meth Project on meth use among youths." Journal of Health Economics 29:5 (2010): 732-742.

[10] Shepard, E. "A new study finds...we wasted billions on DARE." Reconsider Quarterly 1:4 (20012002): 6-11.

[11] Vincus, A. A., C. Ringwalt, M. S. Harris, and S. R. Shamblen. "A short-term, quasi-experimental evaluation of DARE's revised elementary school curriculum." Journal of Drug Education 40:1 (2010): 37-49.

[12] Jeynes, W. H. "The relationship between the consumption of various drugs by adolescents and their academic achievement." American Journal of Drug and Alcohol Abuse 28:1 (2002): 15-35.

[13] McCaffrey, D. F., R. L. Pacula, B. Han, and P. Ellickson. "Marijuana use and high school dropout: The influence of unobservables." Health Economics 19:11 (2010): 1281-1299.

\section{The full reference list for this article is available from the IZA World of Labor website (http://wol.iza.org/articles/does-substance-use-affect-educational-outcomes?).}

